\title{
Resiliency and resource-based communities: a Canadian case study
}

\author{
L. Deacon \& T. Lamanes \\ Department of Earth and Atmospheric Sciences, \\ University of Alberta, Canada
}

\begin{abstract}
Resource-based communities (RBC) are a significant feature of the economic geography of Canada. For many of these economies, particularly those based on minerals and petroleum resources, the past 20 years has witnessed tremendous growth. For example, energy exports contributed $\$ 113$ billion to the Canadian economy in 2011 alone. At the center of this boom is the Regional Municipality of Wood Buffalo (RMWB). Like no other RBC in Canadian history, the region's population has doubled to over 100,000 in less than 10 years. This growth has caused the RMWB to struggle to keep pace with the infrastructural needs of its residents (e.g. health, education, recreation facilities). Despite such concerns, the population of the region is estimated to increase to 250,000 within 30 years. Using the RMWB as a case study, this project examines Canada's premiere resourcebased region from a long-term resiliency perspective. This project uses key informant interviews with local stakeholders to examine local perceptions of growth and development and their impact on community resiliency. We identify resident retention and resident involvement as the two primary concerns of residents linked to resiliency. This exploratory study suggests the need for further research to examine: (1) the perceived linkages between local infrastructural ideals and institutional governance; (2) the potential role of external information sources (e.g. the mainstream media) on perceptions of growth and development; and (3) the need to develop a "tool-kit" of informative resources for future resource-based communities grappling with rapid growth and attempting to become resilient to the associated challenges.

Keywords: resource-based community, sustainability, resiliency, urban planning, community development.
\end{abstract}




\section{Introduction}

This exploratory paper offers an initial snap-shot of how residents of a resourcebased community experiencing rapid growth perceive growth and development and how these concepts impact community resiliency. Resource-based communities (RBCs) are a significant feature of the economic geography of Canada. For many of these economies, particularly those based on mineral and petroleum extraction, the past 20 years has witnessed tremendous growth. For example, energy exports contributed $\$ 113$ billion to the Canadian economy in 2011 alone. At the centre of this boom is the Regional Municipality of Wood Buffalo (RMWB) and its administrative centre, Fort McMurray, Alberta. Like no other RBC in Canadian history, the region's population has doubled in less than 10 years to over 100,000 . The growth has caused the RMWB to struggle to keep pace with the infrastructural needs of its residents (e.g. health, education, recreation facilities). Despite such concerns, the population of the RMWB is estimated to increase to 250,000 within 30 years [1].

This paper links to two primary areas of academic inquiry. First, it contributes to literature on resource-based communities by exploring local perceptions of development and growth in order to highlight the process(es) and concern(s) that may promote - or hinder - resiliency. Second, it contributes to resiliency and sustainability literature by detailing residents' experiences of the planning process perceived to be unfair and non-inclusive by some residents. Through a Canadian case study, we emphasize important deficits in infrastructure in resource-based communities and public participation by recounting experiences of residents from Fort McMurray, Canada. To set the stage for the study, we briefly review the resource-based communities and resiliency literatures to outline the definitions and implications.

\subsection{Resource-based communities}

Thus far, the majority of research on boomtowns has been situated in the United States, focused on 'traditional' resources (e.g. lumber, gold) in small towns (often less than 15,000 people) and considered a range of areas including crime, health, education, social connectedness, and community cohesion [2]. These studies have examined the life-cycle of resource-based communities [3, 4], the interaction between commodity prices and local well-being [5], the social impacts of mine closure [6], rapid resource-sector growth [7], income distribution in resource communities [8], the presence of poverty [9, 10], and the broader political economy of the resource sector [11]. Much of this literature points to the volatile and often problematic relationship between resource extraction and community well-being.

Resource-based communities can be classified as boomtowns when an industrial process, often involving the extraction of energy sources, results in unprecedented population growth and economic development followed by a reversal in growth once the resource has been depleted [12]. The initial industrial activity attracts an influx of people seeking employment opportunities followed by rapid population 
that often strains existing services (e.g. healthcare, schools, retail, childcare) and infrastructure (e.g. transportation and housing) beyond the region's capacity to meet supply [13]. Additionally, this strain often results in social disruption and corresponds with negative impacts on the social and cultural fabric of communities [13]. Challenges exist in retaining the necessary workforce to adequately provide health care, educational, hospitality, and retail services due to wage competition and the inflated cost of living of RBCs [14, 15]. Some researchers claim that longterm residents in boomtown communities eventually adjust to the changes that occur from rapid growth and argue that social ties are not affected; however, newcomers, particularly women, often experience difficulty integrating into the community $[12,16,17]$. The integration of newcomers to these relatively homogenous communities result in changes to traditional routines and attitudes, and can create tensions with existing residents [12]. Despite the economic benefits, long-term residents often become disgruntled with traffic congestion and reduction in services resulting from this rapid growth [12]. Increased crime, alienated youth, social isolation, depression, marital hardship, and substance abuse are said to increase as a result of changes to the social structure in boomtowns [12, $13,18]$.

All of these associated problems potentially limit the development of social bonds that lead to community involvement and place attachment. This is not to suggest that all residents of boomtowns suffer negative effects, and the social disruption model has received criticism within some literature [13]. For example, research conducted by Lawrie et al. [13] in three large Australian boomtowns found that there was a decrease in reported crime as well as improved socioeconomic conditions despite the increase to the cost of living, which is an example of the complex evolution of boomtowns. Also noted in Lawrie et al. [13] was that social disruption was not as pronounced in two out of three urban areas studied, which was thought to result from a more diversified economy and resident work force.

Evidence from much of the literature finds that economic benefits from the industrial activity are not equally distributed amongst the community, which creates economic stresses for residents with lower socio-economic status (SES) [2]. This inequity increases the vulnerability of low-income residents to the bust cycle that occurs when the resource is depleted. When economic activity comes to halt, potentially leaving the area with high levels of unemployment, devalued property and large decreases in population often further exacerbating existing negative social impacts [2]. Ennis et al. [2] also suggest that long term planning and increased community involvement in resource-dependent regions can mitigate some of the social disruption that occurs. If managed properly, the population and economic growth associated with boomtowns can be a driving force for improved infrastructure, services, and economic diversification that increases citizen satisfaction and social cohesion $[18,19]$.

\subsection{Resilience}

"Resilience" was first used by physical scientists to describe the stability of materials and their resistance to external shocks. In the 1960s along with the rise 
of systems thinking [20] resilience entered the field of ecology. In organizational studies, resilience is understood as the capacity of an organization to maintain positive change under challenging conditions wherein under these conditions the end result of the organization emerges both stronger and more resourceful [21]. According to Wildavsky [22] resilience is the ability to cope with and bounce back from unexpected dangers after they have unfolded. Our understanding of the term blends an outcome-oriented approach with a process-oriented appreciation of resilience [23].

Holling [24, 25] blended the ideas of systems theory and ecology to explain ecological systems and other natural and social systems. In two key works [24, 25], he explains resilience in two ways: engineering and ecological. He defined engineering resilience as the ability of a system to return to an equilibrium or steady state after a disturbance; either a natural disaster, such as flooding or earthquakes, or social upheaval, such as banking crises, wars, or revolutions. In this perspective, the resistance to disturbance and the speed at which the system returns to equilibrium is the measure of resilience. In contrast, he defined ecological resilience as the disturbances' magnitude that can be absorbed prior to changes in its structure [25]. Here, resilience is defined not just according to how long it takes for the system to bounce back after a shock, but also how much disturbance it can take and remain within critical thresholds. Ecological resilience focuses on the ability to persist and adapt [26].

Davoudi [27] introduced a third type of resilience: evolutionary resilience. He argues that the nature of systems may change over time with or without an external disturbance. This type of resilience is not conceived of as a return to normality, but rather as the ability of complex socio-ecological systems to change, adapt, and, crucially, transform in response to stresses and strains.

Davoudi [27] is also concerned with translating resilience thinking from the natural to the social world and how society can be understood from the perspective of ecology. In the social world, resilience has as much to do with shaping the challenges we face as in our response to them. Resilience in the social context should, therefore, be coupled with issues of justice and fairness.

\section{Case study}

\subsection{Background}

This case study is part of a larger project investigating the long-term resiliency of resource-based communities. The selected case study was one of a number of potential case studies of resource-based communities across Canada; however, it was the notoriety of Fort McMurray, AB as well as its economic importance within Canada and abroad that brought us to this particular community.

The goal of the research is to understand how residents of a resource-based community perceive the impacts of growth on the long-term resiliency and sustainability of the community. More specifically, the central objective is to examine what residents of a resource-based community experiencing rapid growth and development perceive as the central concern(s) related to the resiliency and 
long-term sustainability of the community. The case study is an investigation of Fort McMurray, Alberta, Canada, which is a community that has been at the epicentre of the Canadian oil sands development. Since this was a qualitative case study, it was open and flexible and was not set up specifically to test the concept of resiliency planning or resiliency more generally; rather, the concept emerged as part of our interpretation of the interviews in combination with existing literature(s). That is, the resource-based community and resiliency literatures were our starting point; rather, the themes within the case study led us to emphasise resiliency planning post hoc - a common strategy to avoid premature interpretive closure in qualitative research $[30,31]$.

\subsection{Case community}

Fort McMurray is the administrative centre of the Regional Municipality of Wood Buffalo (RMWB) located in north-eastern Alberta, Canada, approximately $430 \mathrm{~km}$ from Edmonton, Alberta, the province's capital (fig. 1). The RMWB is the largest municipality in Canada at $66,361 \mathrm{~km}^{2}$, roughly double the size of Belgium. Currently, the RMWB is the site of the largest industrial project in the world. This region is home to the Athabasca oil sands, the world's third largest oil reserve deposit with an estimated 170 billion barrels of recoverable oil. The mining of the oil sands has developed to "mega project" status, and the prolonged life span of bitumen mining is estimated to last up to 100 years. Over the next 25 years, the Athabasca oil sands are expected to contribute \$2,106 billion in GDP to the Canadian economy [32-34].

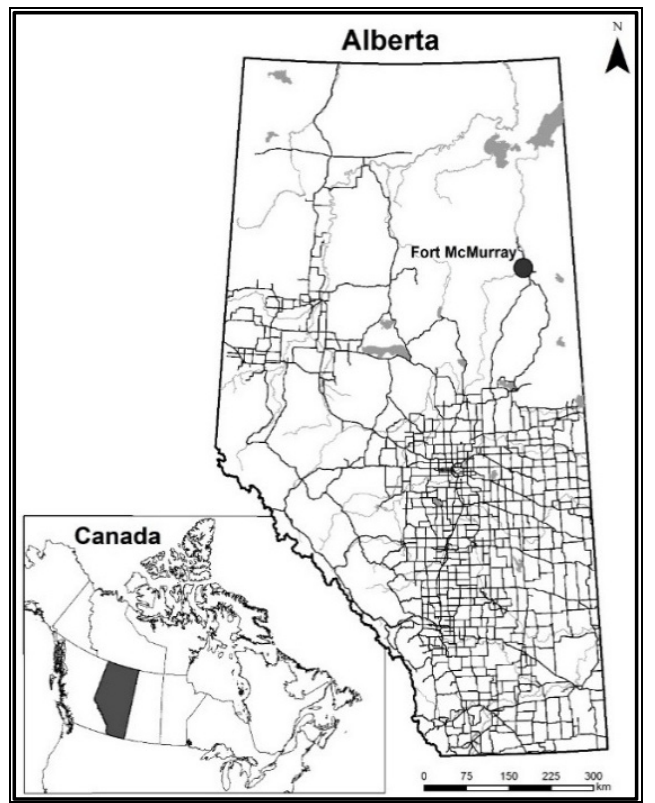

Figure 1: Fort McMurray, Canada. 
The industrial development of the Athabasca oil sands has resulted in rapid population growth mainly due to increased employment opportunities. The population is expected to increase by $121 \%$ reaching an estimated 200,000 by the year 2030 [1]. Due to the rapid increase in population, the RMWB is having difficulty developing the physical and social infrastructural needs of its residents [1]. Traffic congestion is a daily issue due to the influx of workers traveling to and from work sites [14], as well housing shortages, which have caused the average housing price to inflate to $\$ 751,232$ (Canadian average is $\$ 398,000$ ) [1]. The average resident age is 32 years (Canadian average is 41 years), and the average household income in the RMWB is roughly $\$ 189,000$ (Canadian household average $\$ 75,000)[1]$.

\section{Methodology}

This case study involved semi-structured interviews with 18 participants from three distinct groups: (1) long-term residents $(\mathrm{n}=6)$; (2) new residents $(\mathrm{n}=7)$; and (3) non-permanent residents $(\mathrm{n}=5)$. We chose a range of participant types to allow for the exploitation of a diverse set of opinions regarding the development of Fort McMurray in order to develop a robust conceptual understanding of the case.

Heterogeneous maximum variation snowball sampling was used. Participants were asked to recommend 'someone who thinks differently than you do about development in Fort McMurray,' to maximize variation, which typically helps enhance theoretical depth. The sample size was based on the principle of saturation when noticeably little new information was being realized [35]. The 18 interviews were conducted at various locations of the participants' choosing. The interviews averaged approximately $45 \mathrm{~min}$ in length; with some lasting over 80 min and others as short as $30 \mathrm{~min}$. All interviews were conducted with informed consent, taped and transcribed verbatim into a word processor, which translated into over 46,000 words of text, or 130 pages of interviews. These interviews were analysed for emergent themes with the aid of the qualitative software package NVivo 10. The contextualized thematic analysis approach was used, which builds on traditional modes of presentation in interview-based studies and is closely linked to ground-theory analysis [36-38]. Thus, the analysis involved a combination of inter-interview and intra-interview comparisons, as required, to achieve a depth of understanding. Thematic analysis is common in qualitative research, whereby codes (nodes or themes) are ascribed to discrete units of text (quotations) within the interviews; similar to the 'coding and memoing' stages of grounded theory analysis [37]. The term 'theme' can be used to denote the fact that the data are grouped around a central theme or issue [39]. Unless otherwise indicated, quotations were selected for presentation if they were representative of all quotations for a theme. Pseudonyms are used to identify speakers.

\section{Case study findings}

Findings from this case study focused on some of the contextual issues related to development and participation and how these issues may negatively impact the 
long-term resiliency of Fort McMurray. Specifically, issues related to healthcare infrastructure and civic participation was prominent.

\subsection{Development, participation and resiliency}

Our primary objective was to explore local perceptions of development and growth in order to begin to shed light on the process(es) and/or concern(s) that may promote - or hinder - resiliency. It is worth noting that nearly $100 \%$ of all participants $(\mathrm{N}=16)$ were supportive of Fort McMurray and the opportunities that the community has provided them.

However, when participants were asked about their own reservations regarding the impact of the booming economy on the resiliency and long-term sustainability of the community, the most frequently mentioned issues centred on resident retention and involvement. More specifically, 1) promoting long-term residents and family growth by ensuring that there is adequate care facilities for new or expecting mothers (e.g. gynaecologists) $(\mathrm{N}=11) ; 2)$ provide infrastructure to enable residents to retire and age-in-place $(\mathrm{N}=8)$ and; 3) providing an opportunity for genuine participation throughout municipal governance matters $(\mathrm{N}=11)$.

Beginning with resident retention, the importance of adequate health-care facilities were listed as the single most important factor for people when they are deciding whether to permanently settle in Fort McMurray. Erin, a relatively new resident of Fort McMurray (under five years) described the difficulty for female residents to find a gynaecologist who is accepting new patients and even if they are successful, she felt, that her health concerns are still not being taken as seriously as others:

"Even if you do get a gynaecologist, you're not a priority because there are over 100 babies born here a month. So just to try to call in and get a general appointment, you are the lowest on the list. It doesn't matter. I've waited in waiting rooms for hours and actually left because there's no point to staying because I knew everyone else was ahead of me."

Gabe, a long-term resident and newly married, has been having discussion with his wife about starting a family and putting down "permanent roots" in Fort McMurray. However, he described the importance of securing a family doctor not only for his wife but for the care of their unborn children:

"I don't have a family right now, but we're talking about it, and that's one of our biggest concerns about having a baby, is the lack of doctor and medical care for women ... and for the child."

A second concern related to health care that was frequently discussed was the ability, or inability, of older residents to retire in the community. Jackie, another long-term resident (more than 20 years), noted the ability of residents to complete the "full life-cycle" was nearly impossible given the current lack of necessary infrastructure: 
"Yeah, well, there's no long-term care facility in Fort McMurray and that's a big factor to retaining our seniors here (...) to bring them through the complete life cycle."

While not all participants voiced concern with the current long-term health facilities in Fort McMurray, perhaps it was more a function of their own long-term plans. For example, Brae, who has been a resident of the community for just over six years, is aware about the general concern regarding long-term health facilities, but does not worry about it affecting her personally because she has no plans to retire in Fort McMurray:

"I'm familiar with the concern, and I am slightly familiar with the concern right now that there isn't one (a long-term health care facility), and I guess maybe because I don't plan to retire here it doesn't fit my radar."

In addition to concerns about healthcare, the process of community engagement and consultation was mentioned as a potential limitation to growth and development. Eleven residents were critical of the process of development within the community, feeling that while there are opportunities for residents to participate in community decision-making, the perception is that this was lipservice rather than true public participation. Keegan, a long-term resident, felt that residents have little-to-no serious impact on decisions made in the community:

"No, I'm going to say no. I'm going to say a big fat no on that. I think they kind of give you an illusion that you do (have opportunities to participate in community decision-making). They (i.e. local government) do a lot of open houses and stuff like that but I think at the end of the day, they have their agenda set and that's the way it is."

Jonathon, a long-term resident (over 10 years) reiterated Keegan's perception that there was an agenda and that the concerns of residents were not given full consideration during municipal decision-making and planning initiatives:

“No, no I don't, I think ... I think it's like ... there's like very surface inclusion (in decision making) ... What my experience is that it's announced (a municipal decision) and all the benefits are what's really focussed on, but a realistic timeframe of when things are going to happen and opportunity for public participation (in the decision) is not a real concern."

Even if there is opportunity for citizen engagement, some residents feel disenfranchised because the same group of people are always involved and an effort to engage the entire community is not made. Joey, another long-term resident (over five years), perceives that while there may be adequate opportunity to become involved and voice one's opinion, it's more often-than-not the same group of people who actually influence the decision-making: 


\begin{abstract}
"There are lots of ways or types of engagement services conducted by the city but it's always the same group of people ... the same group of people running the sessions and it's the same group of people attending them. Everyone here is too busy to get involved in every little engagement sessions. That's the way it is in company towns."
\end{abstract}

\title{
5 Discussion/conclusions
}

This study opens up new avenues of focus within the debate on resiliency and resource-based communities. The Fort McMurray case study illustrates some of the serious concerns of residents in a resource-based community grappling with long-term resiliency. This work is exploratory and intentionally selective to highlight local perceptions of development and growth.

We highlight that local residents perceive resident retention and infrastructural capabilities to be interrelated and important in a resource-based community. More specifically, as highlighted often, deciding whether or not to stay as a long-term resident largely depends on whether or not adequate healthcare needs are being met. This echoes earlier work that highlights the impact of rapid population growth on infrastructure and its impacts on the social and cultural fabric of a community [13]. In particular, our findings show that difficulty for women to find appropriate healthcare are corroborated by previous findings $[12,16,17]$. Previous resourcebased community research [12] has indicated that long-term residents may become unhappy with some of the consequences of the growth (e.g. traffic congestion), this was not echoed by our sample participants. Rather, as indicated above, many of the participants described how the community of Fort McMurray has provided them opportunities for employment and experience they would not have been able to find in other Canadian communities. This is not meant to indicate that the residents of Fort McMurray are without concern. For example, in relation to traffic-related complaints, the lack of perceived concern may be related to recent transportation upgrades that were complete previous to the interviews and therefore did not appear in the interviews.

In addition, we highlight the importance of true citizen control in local decision-making and engagement from across the community [41]. As echoed in previous research [2] the benefits of increased community involvement have been linked to a range of areas including decreased social disruption and improved social cohesion and citizen satisfaction - all of which are related to resiliency and long-term sustainability of a community.

We highlight how the infrastructural needs of a community, especially healthcare, are related to its critical threshold and, according to participants, Fort McMurray is on the verge of surpassing this critical tipping point. The community may become unable to sustain its growing population without needed investment (e.g. increase gynaecologists). While experiencing a resource-boom may not be a traditional external stress, they are without doubt challenging conditions. Viewed from an evolutionary resilience viewpoint [27], these areas of perceived concern require the community to be able to adapt and transform to related stresses. If true 
resilience is to be achieved, it is imperative that the community of Fort McMurray and its residents work together to improve the capacity to be able to emerge strong and more resourceful.

\section{Future directions}

This case study highlights that the concept of resiliency may be difficult to achieve in a community experiencing extraordinary growth. This exploratory study adds to the resource-based community and resiliency literature by examining the local perceptions related to growth and development and their impacts on achieving or hindering - resiliency. However, this study opens up new avenues for research in the area of resiliency in several areas. First, in terms of approaches to research, it would be useful to explore more deeply how specific infrastructure ideals are linked to institutional governance and structures - e.g. using AlQahtany [41]. Second, it would be useful to examine how the role of external information sources (e.g. the media) are able to affect local perceptions of growth and development and hence overall resiliency. Third, a more detailed case-study further examining specific elements mentioned by participants - e.g. maternal health and age-in-place - as they relate to a resource-based community context. Fourth, questions remain regarding how the idea of resiliency can be employed as a method of resistance against additional unsustainable growth in future resourcebased communities in Canada and across the globe. Fifth, and perhaps most importantly, there is a need to develop a tool-kit of suggestions and ideas for other resource-based communities - especially in the developing world - to avoid the mistakes of the past.

\section{Acknowledgements}

We would like to acknowledge the contribution of Pam Keegan for her editing and Larry Laliberte for the design of Figure 1.

\section{References}

[1] Regional Municipality of Wood Buffalo. Municipal Census, 2012.

[2] Ennis, G., Finlayson, M., \& Speering, G., Expecting a boomtown? Exploring potential housing related impacts of large scale resource development in Darwin. Journal of Studies and Research in Human Geography, 7(1), pp. 33-42, 2013.

[3] Halseth, G., "We came for the Work": Situating Employment Migration in BC's Small, Resource-based, Communities. The Canadian Geographer/Le Géographe Canadien, 43(4), pp. 363-381, 1999.

[4] Lucas, R. (1971). Minetown, Milltown, Railtown: Life in Canadian Communities of Single Enterprise.

[5] Freudenburg, W.R., Addictive economies: extractive industries and vulnerable localities in a changing world economy. Rural Sociology, 57(3), pp. 305-332, 1992. 
[6] Bradbury, J.H., \& St-Martin, I., Winding Down in a Quebec Mining Town: A case study of Schefferville. The Canadian Geographer/Le Géographe Canadien, 27(2), pp. 128-144, 1983.

[7] Smith, M.D., Krannich, R.S., \& Hunter, L.M., Growth, Decline, Stability, and Disruption: A Longitudinal Analysis of Social Well-Being in Four Western Rural Communities. Rural Sociology, 66(3), pp. 425-450, 2001.

[8] Leatherman, J.C., \& Marcouiller, D.W., Income Distribution Characteristics of Rural Economic Sectors: Implications for Local Development Policy. Growth and Change, 27(4), pp. 434-459, 1996.

[9] Randall, J.E., \& Ironside, R.G., Communities on the Edge: An Economic Geography of Resource-Dependent Communities in Canada. The Canadian Geographer/Le Géographe Canadien, 40(1), pp. 17-35, 1996.

[10] Wilson, D., Toward a Contingent Urban Neoliberalism. Urban Geography, 25(8), pp. 771-783, 2004.

[11] Barnes, T., \& Hayter, R., Troubles in the Rainforest: British Columbia's Forest Economy in Transition. Western Geographical Press, 1997.

[12] England, J., \& Albrecht, S., Boomtowns and social disruption. Rural Sociology, 49(2), pp. 230-246, 1984.

[13] Lawrie, M., Tonts, M., \& Plummer, P., Boomtowns, resource dependence and socio-economic well-being. Australian Geographer, 42(2), pp. 139$164,2011$.

[14] Nikiforuk, A., El Dorado north. Planning, 77(7), pp. 40-46, 2011.

[15] Meinert, D., Hiring Frenzy. HR Magazine, 58(6), pp. 30-37, 2013.

[16] Freudenburg, W., Women and men in an energy boomtown: Adjustment, alienation and adaptation. Rural Sociology, 46(2), pp. 220-244, 1981.

[17] Albrecht, S.L., Socio-cultural Factors and Energy Resource Development in Rural Areas in the West. Journal of Environmental Management 7, pp. 73-90, 1978.

[18] Franks, D., Social impact assessment of resource projects. International Mining for Development Centre, 3, 2012.

[19] Beauvais, C., \& Jenson, J., Social Cohesion: Updating the State of the Research. CPRN Discussion Paper No. F22, 2002.

[20] Luhmann, N., The World Society as a Social System. International Journal of General Systems, 8(3), pp. 131-138, 1982.

[21] Vogus, T.J., \& Sutcliffe, K.M., Organizational resilience: Towards a theory and research agenda, in: IEEE, pp. 3418-3422, Oct. 7-10 2007.

[22] Wildavsky, A., Searching for Safety. New Jersey: New Brunswick Transaction, 1988.

[23] White, I., Water and the City. Risk, Resilience and Planning for a Sustainable Future, London/New York: Routledge, 2010.

[24] Holling, C.S., Resilience and Stability of Ecological Systems. Annual Review of Ecology and Systematics, 4(17), pp. 1-23, 1973.

[25] Holling, C.S., Engineering Resilience versus ecological resilience, in: P.C. Schulze (Ed.) Engineering within Ecological Constraints, Washington, DC: National Academy Press, pp. 31-44, 1996. 
[26] Adger, W.N., Building resilience to promote sustainability, IHDP Update, 2, pp. 1-3, 2003.

[27] Davoudi S., Resilience: A Bridging Concept or a Dead End? Planning Theory \& Practice, 13(2), pp. 299-307, 2014.

[28] Shaw, K., 'Reframing' Resilience: Challenges for Planning Theory and Practice. Planning Theory and Practice, 13(2), pp. 309-310, 2012.

[29] Vale, L.J., The Politics of Resilient Cities: Whose Resilience and Whose City? Building Research \& Information, 42(2), pp. 191-201, 2014.

[30] Miles, M.B. and Huberman, A.M., Qualitative data analysis: an expanded sourcebook. Thousand Oaks, CA: Sage, 1994.

[31] Morse, J.M., Barrett, M., Mayan, M. et al., Verification strategies for establishing reliability and validity in qualitative research. International journal of qualitative methods, 1(2), pp. 13-22, 2002.

[32] Canadian Energy Research Institute, Study 124: Economic Impacts of New Oil Sands Projects in Alberta, pp. 2010-2035, 2011.

[33] Dorow, S. \& O'Shaughnessy, S. (2013). Fort McMurray, Wood Buffalo, and the oil/tar sands: Revisiting the sociology of 'community'. Canadian Journal of Sociology, 38(2), pp. 121-140, 2013.

[34] Regional Municipality of Wood Buffalo Economic Development, Canada's Greatest Economic Treasure, 2014.

[35] Morse, J.M., Determining sample size. Qualitative health research, 10(1), pp. 3-5, 2000.

[36] Patton, M.Q., Qualitative evaluation and research methods. $2^{\text {nd }}$ ed. Thousand Oaks, CA: Sage, 1990.

[37] Willms, D., Best, J.A., Gilbert, J.R. et al, A systematic approach for using qualitative methods in primary prevention research. Medical anthropology quarterly, 4, pp. 391-409, 1990.

[38] Denzin, N.K., \& Lincoln, Y., Qualitative Research. Thousand Oaks CA: Sage, 2000.

[39] Brink, P. and Wood, M., eds., Advanced design in nursing research, Thousand Oaks, CA: Sage, 1994.

[40] Arnstein, S. R., A Ladder of Citizen Participation. Journal of the American Planning Association, 35(4), pp. 216-224, 1969.

[41] AlQahtany, A., Rezgui, Y., \& Haijiang, L., A proposed model for sustainable urban planning development for environmentally friendly communities. Architectural Engineering and Design Management, 9(3), pp. 176-194, 2013. 